\title{
1Malaysia English Reflects Unity
}

\author{
Jantmary Thirusanku ${ }^{1} \&$ Melor Md Yunus ${ }^{1}$ \\ ${ }^{1}$ Faculty of Education, National University of Malaysia, UKM, Bangi, Selangor Darul Ehsan, Malaysia \\ Correspondence: Jantmary Thirusanku, 7, Lorong Batu Unjur 3B, Bayu Perdana, 41200 Klang, Selangor, \\ Malaysia. Tel: 60-19-250-1828. E-mail: eambjs@gmail.com
}

Received: July 10, $2014 \quad$ Accepted: August 2, $2014 \quad$ Online Published: August 14, 2014
doi:10.5539/elt.v7n9p105
URL: http://dx.doi.org/10.5539/elt.v7n9p105

\begin{abstract}
The main aims of this qualitative study are to identify and categorise the types of lexical borrowings from the three main Malaysian languages which are the Malay language, Chinese dialects and Indian languages used by 203 ESL teachers, to what extent these lexical borrowings are used and for what reasons. This study has identified a new category known as prefixation and collected 483 lexical items over a period of one year that is, from December 2011 to November 2012. The findings of this study show that the ESL teachers mainly use the lexical items from the Malay language more frequently as it is the official language and has a prestigious placing. Since unity in diversity is encouraged, 1Malaysia English will further unite the Malaysians and thus accept the 1Malaysia concept with a more open and positive mind.
\end{abstract}

Keywords: ESL teachers, lexical borrowings, Cohen's Kappa, 1Malaysia English

\section{Introduction}

The emergence of the Malay language as the medium of instruction in the government schools in Malaysia had considerable influence on the local usage of English. Firstly, there was frequent code-switching by the second generation of Malaysians, namely those who entered schools in 1980 and later. They are far familiar with colloquial expressions in Bahasa words and expressions to convey what they mean when speaking English to their fellow Malaysians and even when using their native language within their own communities. Besides this, they also resort to code-mixing whereby Bahasa roots are combined with English affixes e.g. "cacated", meaning awkward or improper. Bahasa words are also combined with English words to form compounds e.g. "kampung house". In other words, lexico-semantic features of local languages such as Malay have begun to creep into the English language spoken by Malaysians who have received their formal education in Malay medium.

While this feature is also found in the English language spoken by the first generation of Malaysians who have received their formal education in the English language, there is a distinctive difference between the first generation and the second generation. While the younger generation tends to be also influenced by the syntax and grammar of Bahasa in their Malaysian English, members of the older group have retained the syntax and grammar of Standard British English when writing or speaking the English language. This is because they have a stronger foundation in the English grammar, having benefited from the system where English was the medium of instruction (Menon, 2003, p. 33).

However, like the younger generation, many have diverged from the Standard British English, in terms of lexis and semantics of spoken English. Words and even idiomatic expressions from Bahasa Melayu, Cantonese, Hokkien, Tamil and other languages have been extensively borrowed and a range of native English words have acquired new meanings or new connotations.

The English language which has emerged from all those influences has been termed "Malaysian English" (ME). There may be three viewpoints which account for the emergence of Malaysian English in terms of lexis. The first viewpoint is that of psycholinguists and language educators regard ME to be a result of "fossilized errors" acquired during the language acquisition process. ME may be regarded as a permanent sort of "interlanguage" (Selinker, 1972), which consists of a large number of fossilized phonological, semantic and syntactic errors. The second viewpoint is that of sociolinguists, regard $\mathrm{ME}$ as a result of an acculturation process of language transfer whereby cultural features from the mother tongue of the different ethnic communities have permeated the English language used locally. While certain aspects of ME may be a result of language transfer, it is believed that this may be only one of the factors leading to the creation of ME. The third viewpoint is that, ME may be the 
result of a creative process whereby both common cultural features as well as aspects of learner strategies such as creativity and redundancy may be resulted in a variety of English which may be regarded as uniquely Malaysian (Menon, 2003, p. 34).

Any attempt to describe Malaysian English should take into consideration Malaysian's cultural diversity as well as regional differences. The two parts of Malaysia are separated from each other by the South China Sea: Peninsular Malaysia and Sabah and Sarawak on the island of Borneo. The population is about 28.31 million with the main ethnic groups being Malay (65.9\%), Chinese (25.3\%) and Tamil (7.3\%) (Department of Statistics Malaysia, 2010). The Malays in Malaysia consist of Austronesian speakers and the Austroasiatic speakers with the latter belonging to the aboriginal tribes. The other groups, the Chinese and Indians, also have a number of dialects and languages. Together with the other minority groups, like the Eurasians, Arabs, Thais and Europeans, they have contributed to the rich tapestry of ME. Due to educational policies and history, most Malaysians can speak two or more languages (Low \& Azirah, 2012, p. 56). Table 1 is a summary of the main languages spoken by Malaysians.

Table 1. Languages spoken by the different ethnic groups (Baskaran, 2004)

\begin{tabular}{ll}
\hline Ethnic group & Languages spoken \\
\hline Austronesians: Malays in West & Bahasa Melayu \\
Malaysia, Kadazans/Dusun, Bajau, & Kadazan, Dusun, \\
Murut, Melanau and Dayaks of Sabah & $\begin{array}{l}\text { Iban, Tagol Murut, Melanau } \\
\text { and Sarawak }\end{array}$ \\
Austroasiatics: Malays in West Malaysia & Tehasa Melayu \\
Settler population: Chinese, Indians, & Hokkien, Cantonese, Hakka, Teochew, \\
Arabs, Eurasians, Thais, Europeans. & Hainanese, Mandarin \\
& Tamil, Malayalam, Telugu, Punjabi, \\
& Bengali, Gujerati, Singhalese \\
& Arab \\
& Thai \\
& Bahasa Melayu \\
& English \\
\hline
\end{tabular}

Just like all the other New Englishes, Malaysian English has some linguistic features which are distinctive due to transfer from the local languages or acculturation. These new varieties have been viewed by some language purists as different from the native speakers' norms due to the lack of approximation of the language. Therefore, many studies on error analysis and contrastive analysis were carried out (Chalaya, 2008, p. 17). To rectify these misinterpretations, more studies on the local varieties of English are needed. The literature on Malaysian English is not even as comprehensive as the literature on Singapore English. Much needs to take place before Malaysian English can be described and codified correctly.

Strevens (1981, p. 3), claims "the proliferation of forms of English is taking place faster than the description of them". This is due to the fact that it is not easy to provide a detailed description of new varieties because of the fast changes and adaptations from local languages that the new varieties experience. Therefore, it is important to note and examine the variations so that it can be termed as a valid variety. Hence, the focus of this study is to present an explanation of the characteristics of ME used by the ESL teachers. ESL teachers are supposed to be competent in the English language but yet consciously use ME.

Hence, the focus of this study is to look at the extent of usage of Malaysian English lexis by 486 English as Second Language (ESL) teachers. This study involved 38 urban and semi-urban National Secondary schools in the Klang district, in Selangor. Therefore, the location of the ESL teachers will not affect the data collection in any way. The number of schools and the distribution of the ESL teachers according to race in the district were checked and verified with Encik Mohd. Hanapi bin Mohd. Daud who is the Klang District Education officer. The contributions of lexical items were from 203 ESL teachers out of the total population of 486 ESL teachers in the district. The ESL teachers were of Malay, Chinese and Indian origin.

This study helps to shine more light on the type and direction of borrowing and reasons for borrowing when languages are in contact. It focuses on the types of lexical items used by these ESL teachers. It also aims to find out the use of lexical items by these ESL teachers, the extent and the purpose of use. There are not many 
intensive studies on the subject based on data collected from the ESL teachers, even though, there is an extensive history of contact between the Malay, Chinese and Indian languages in Malaysia.

There is insufficient research on the variety of English used by ESL teachers in countries with ESL status. Likewise, insufficient research on the variety of English used by ESL teachers in Malaysia. There is also insufficient studies on the lexis of ME specifically, compared to studies on the lexis of Singapore English, Nigerian English and Indian English (Chalaya, 2008, p. 16). Therefore, the intentions of this study are to fulfil this quality and stress on the importance of presenting ME as a legitimate variety rather than a sub-standard variety. The focus is on the lexical aspect of Standard ME or the acrolectal variety which is used by the ESL teachers. (Baskaran, 1987, p. 53) claims, "the variation in the lexical aspect is acceptable especially for words not substitutable in an international context to give a more localised context and has international intelligibility".

Hence, this research aims to record the lexical items in Malaysian English in order to provide more information on the variety of English used by the ESL teachers in Malaysia. This study is significant as it consists of both spoken data and written data from competent ESL teachers and yet consciously use ME. As such, only lexical items from the Malay, Chinese and Indian languages were gathered. Lexical items that were not taken into consideration were foreign culture and acronyms from the Malay, Chinese and Indian languages. With this intensive and comprehensive study on the aspect of ME lexis, the question of lack of research in this field is fulfilled to a certain extent.

\section{Methodology}

This research is based on 14 different categories of lexical items used by the ESL teachers. The lexical items were classified under 4 different researchers namely, Baskaran (1987), Lowenberg (1986), Anthonysamy (1997) and Ooi (2001). While analyzing the data, the distinctive lexical items used by the ESL teachers were highlighted. The researcher encountered a new category, prefixation in the midst of the research. Table 2 shows the 14 categories plus, the new category, prefixation for the classification of the lexical items and the names of the researchers.

Table 2. The categorization of the lexical items in this research

\begin{tabular}{|c|c|c|c|c|c|c|}
\hline No & Classification & $\begin{array}{l}\text { Baskaran } \\
(1985,1987)\end{array}$ & $\begin{array}{l}\text { Lowenberg } \\
\text { (1986) }\end{array}$ & $\begin{array}{l}\text { Anthonysamy } \\
\text { (1997) }\end{array}$ & $\begin{array}{l}\text { Ooi } \\
(2001)\end{array}$ & $\begin{array}{l}\text { Thirusanku } \\
\text { (2013) }\end{array}$ \\
\hline 1 & Conversion & $\sqrt{ }$ & & & & \\
\hline 2 & Pluralisation & $\sqrt{ }$ & & & & \\
\hline 3 & Polysemic variation & $\sqrt{ }$ & & & & \\
\hline 4 & Connotative borrowings & $\sqrt{ }$ & & & & \\
\hline 5 & Suffixation & $\sqrt{ }$ & & & & \\
\hline 6 & $\begin{array}{l}\text { Lexical items functioning as a } \\
\text { metaphor }\end{array}$ & $\sqrt{ }$ & & & & \\
\hline 7 & Apostrophe showing possession & $\sqrt{ }$ & & & & \\
\hline 8 & Compounding & $\sqrt{ }$ & & & & \\
\hline 9 & Cultural loading & $\sqrt{ }$ & & & & \\
\hline 10 & Institutional concepts & $\sqrt{ }$ & & & & \\
\hline 11 & Culinary loading & $\sqrt{ }$ & & & & \\
\hline 12 & Lexical shift & & $\sqrt{ }$ & & & \\
\hline 13 & Transfer & & & $\sqrt{ }$ & & \\
\hline 14 & $\begin{array}{l}\text { Hybrids of non-English origin } \\
\text { used in formal and informal } \\
\text { situations }\end{array}$ & & & & $\sqrt{ }$ & \\
\hline 15 & Prefixation & & & & & $\sqrt{ }$ \\
\hline
\end{tabular}

The data consisted of both "written data" and "spoken data" by the ESL teachers. The "written data" refers to Malaysian English lexis derived from sources such as, yearly scheme of work, daily lesson plans, programme reports, sample essays, speeches, textbooks, reference books and workbooks written by ESL teachers, seminar papers, classroom presentation write-ups, newspaper articles, reports, memos/messages and e-mail messages written by ESL teachers. 
The "spoken data" consisted of Malaysian English lexis which were recorded during classroom teaching and learning activities, talks/speeches, seminar papers, meetings, discussions, reports on observation of ESL trainees, conference presentations, teachers' guidance in English language activities and competitions such as, Public Speaking, Drama, Story-Telling, Choral Speaking and Debate, announcements, phone conversations, English language society meetings and conversation with administrators, teachers, friends and family members.

The data was based on spoken and written lexical items. The lexical items were collected from 203 out of 486 ESL teachers. The ESL teachers were from 38 National Secondary Schools in the Klang district, Selangor. The lexical items were identified and recorded from December 2011 to November 2012. The ESL teachers were selected as the sample to show that they are competent in English language and yet consciously use Malaysian English. These ESL teachers assist students who hardly speak English improve their speaking and writing skills and also comprehend the different elements of the Malaysian culture. Therefore, for the ESL teacher to achieve his daily objectives of the learning process the usage of the Malaysian variety is vital to comprehend not only the language but also the cultural differences that exist in Malaysia. The learners are from different educational background, languages and cultures. Due to this, ESL teachers are very vital in imparting knowledge to the learners from all walks of life. ESL teachers have to use the appropriate language to captivate the learners. Hence, the ESL teachers have to be equipped with some basic knowledge of the culture of the society before they face the learners.

The data comprises lexical borrowings in the acrolect of the spoken and written discourse. These lexical items do not have exact equivalents in the Standard English. Thus, only lexical borrowings from the Malay language, Chinese dialects and the Indian languages were collected. To make sure that the lexical borrowings collected were from the Standard Malaysian variety, the lexical items were first checked in three dictionaries which compare Singaporean and Malaysian English with British and American usage. The dictionaries were Grolier International Dictionary (2000), Macquarie Junior Dictionary (1999) and Times-Chambers Essential English Dictionary (1997). When the lexical item exists in either one of the dictionaries, the specific lexical item is then confirmed based on the findings of Malaysia English research by previous researchers. The dictionaries were used as references but the deciding factor was the agreement of the lexical items between two raters. The lexical items were rated "Acceptable" with a tick $(\sqrt{ })$ or "Unacceptable" with a cross (x) by two experienced ESL teachers. The ESL teachers are experts in Malaysian English as they have done studies related to Malaysian English. The interrater agreement was then calculated using Cohen's Kappa which is an index that measures interrater agreement for categorical (qualitative) items. The items are indicators of the extent to which two raters who are examining the same set of categorical data, agree while assigning the data to categories (Choudhury, 2010, p. 1).

According to information in the internet (Audience Dialogue, 2006), there are two ways of doing observation, that is, informal observation and formal observation. Informal observation is also called unstructured or exploratory observation. This means watching and listening to people, usually in public places and trying to form some ideas about their behaviour, knowledge and beliefs. The subject of observation is usually a community or a large group of people, not one person or a single family. It is not enough simply to observe people, the results of observation are not useful unless they are recorded and considered. The best way to do informal observation is to always carry a small notebook and pen.

On the other hand, a formal observation, also called structured or systematic observation is where particular types of behaviour are looked for and counted. No questions are asked. Instead of asking questions, the observer watches people and records their behaviour. One difference between a normal survey and formal observation is that, observers often go beyond observation and ask people "Why do you do that?" You are not observing for the sake of observing but to find out why people act as they do.

Therefore, the researcher decided that the spoken data will be collected in two ways, that is, through an informal observation and formal observation. An informal observation is where the spoken data was recorded manually using a pencil and notebook without the knowledge of the ESL teachers anytime, anywhere. The data was recorded manually there and then in the form of sentences with a pencil in a notebook. The data was not recorded using a hand phone or any other device because it would be too late for the researcher to take out the device to record the sentences used by the ESL teachers as it can occur anytime, anywhere. Therefore, the researcher was alert at all times and immediately recorded manually in a notebook whenever a lexical item was used by any of the 486 ESL teachers in the Klang district. This was done whenever and wherever the researcher meets an ESL teacher. It can be during a formal or informal meeting from December 2011 to November 2012. The formal observation on the other hand, was carried out during the actual teaching and learning process. This was recorded using a high quality MP3 recorder with the ESL teacher's permission. The researcher carried out a 
formal observation of 38 ESL teachers from the 38 schools in the Klang district, which means one formal observation in each school, which came up to 38 formal observations.

As stated earlier, in order for the formal observation to be successful, one must often go beyond observation. Therefore, the researcher asked the 38 ESL teachers the possible reason for the use of the lexical item after the formal observation.

The period during which the data was collected was from December 2011 to November 2012. During this time, the spoken (formal and informal observation) and written lexical items were collected daily. The data collection period of twelve months was considered sufficient. This was because the time span covered all the important festivals held in Malaysia, such as Hari Raya Aidilfitri, Gong Xi Fa Cai, Thaipusam, Ponggal, Vaisakhi and Diwali took place. Therefore, rich sources of lexical items were anticipated during the festival. The data was presented in whole sentences in order to show the context of usage of the particular lexical item. The lexical items were collected solely from the 486 ESL teachers in the Klang district so that the natural use of lexical items by the ESL teachers was ensured. Foreign issue or culture, places names, borrowings for fauna and flora, titles and acronyms such as, Penilaian Menengah Rendah (PMR) were excluded.

The data in this research consists of lexical items that were recorded from 486 ESL teachers' speech (formal and informal observation) and written forms. The researcher then categorized the lexical items under the frameworks mentioned earlier. The lexical items were mostly grouped under Baskaran's $(1985,1987) 11$ categories. She has classified the lexical items into two main categories, namely, Substrate Language Referents and Standard English Lexicalization. The Substrate Language Referents refer to lexical items from the Malay, Chinese and Indian languages, while the Standard English Lexicalization refers to English words adapted to be used in ME. According to Baskaran (1985, p. 85), sub-categories exists within each category which "are representative enough although they are not necessarily exhaustive". Table 2 shows all the 11 categories of Baskaran, another 3 categories by three other researchers and one new category, prefixation encountered in the midst of the research by the researcher. The 14 categories were selected carefully as they were appropriate, most systematic and they covered generally most of the lexical items used in Malaysian English. The researchers involved in this framework were also well-versed in this field, especially Baskaran who is a pioneer in this area. The selection of categories was done carefully in order to avoid overlapping of categories. The 14 main categories selected plus the 1 new category encountered during the research were an intensive and extensive choice of categories with 6 sub-categories for the main category cultural loading and 4 sub-categories for the main category culinary loading.

Firstly, this study identified the lexical items in the spoken or written data. The spoken and written data were collected systematically from the various sources highlighted earlier which contained the acrolectal of Malaysian English. The lexical items were presented in whole sentences in order to show the context of usage of the particular lexical item. The spoken data was collected in two ways, that is, through an informal observation and formal observation. As mentioned earlier, an informal observation is where the spoken data was recorded manually in a notebook with a pencil without the knowledge of the ESL teachers. The researcher was alert at all times and immediately recorded manually whenever a lexical item was used by any of the 486 ESL teachers in the Klang district. This was done whenever and wherever the researcher meets an ESL teacher. It can be during a formal or informal meeting from December 2011 to November 2012. On the other hand, a formal observation was carried out during the actual teaching and learning process. This was recorded using a MP3 recorder with the ESL teacher's permission. A formal observation of 38 ESL teachers from 38 schools in Klang was carried out which means, one formal observation in each school, which came up to 38 formal observations. All the lexical items collected were categorized with reference to the 14 categories plus 1 new category encountered in the midst of the research in separate tables according to the three main Malaysian languages. The lexical items were analyzed and rated as they were collected.

The lexical items related to cultural loading were sub-categorised namely; religious terms, traditional festivals and religious observances, the art of self-defence and exercises, traditional clothes, traditional games and traditional musical instruments and dances. The lexical items in the form of sentences were analyzed after every table and an explanation on the possible reasons for the use of these lexical items were followed. Every sentence has a description of which school the ESL teacher is from, the race (Malay/Chinese/Indian), gender (male/female), age when the lexical item was collected and the source. The possible reasons were based on the interpretation of previous researchers and also from the ESL teachers themselves through a standardized, open-ended question. Here, the same open-ended question was asked to all the $38 \mathrm{ESL}$ teachers after the formal observation, i.e. "What's the possible reason for the use of this lexical item?" An open-ended question is where respondents are free to choose how to answer the question, i.e., they do not select "yes" or "no" or provide a 
numeric rating. This approach facilitates a faster session that can be more easily analyzed and compared. Finally, the six sub-categories were summarized according to the three main languages in Malaysia in a main table. This was done for all the other 13 categories plus the new category.

Each lexical item in each category was rated "Acceptable" with a tick $(\sqrt{ })$ or "Unacceptable" with a cross (x) by two raters A and B. Since the researcher decided to use Cohen's Kappa which measures agreement between two raters only, two ESL teachers were used as raters. Both the raters were chosen because they are experts in the field of Malaysian English as they have done studies related to Malaysian English. One Malay teacher and another Chinese teacher were chosen so that the lexical items were fairly rated as this study involved the collection of lexical items from the three main Malaysian languages. Both the raters were ESL teachers from SMK Sri Istana, Klang, Madam Zee, a Malay, female in her 30s with 15 years of experience (Rater A) and Mr. Dee, a Chinese, male in his 50s with 30 years of experience (Rater B). This was to identify the rate of agreement between the raters using Cohen's Kappa, an index that measures interrater agreement for categorical items (Choudhury, 2010, p. 1). This was done to show the reliability level of the study. As the lexical items were collected and analyzed they were also rated a few at a time, by raters A and B. The lexical items were presented in separate sheets to the raters, so that the raters will not be influenced with each other's rating. But at the end of the analysis when the lexical items were presented, the raters selection of whether "Acceptable" or "Unacceptable" were presented side by side for comparison.

Lastly, the lexical items collected were categorised into the respective 14 categories plus 1 new category and analyzed based on the extent of use as shown in Table 3. The categories were classified in descending order based on the frequency count of the occurrences of the lexical items.

Table 3. Collection of lexical items based on the three main languages in Malaysia

\begin{tabular}{|c|c|c|c|c|c|c|c|c|c|c|}
\hline \multirow{2}{*}{ Categories } & \multirow{2}{*}{ Malay } & \multirow{2}{*}{ Chinese } & \multirow{2}{*}{ Indian } & \multirow{2}{*}{$\begin{array}{l}\text { English/ } \\
\text { Hybrid }\end{array}$} & \multirow{2}{*}{ Total } & \multirow{2}{*}{$\%$} & \multicolumn{2}{|c|}{ Rater A } & \multicolumn{2}{|c|}{ Rater B } \\
\hline & & & & & & & $\sqrt{ }$ & $\mathrm{x}$ & $\sqrt{ }$ & $\mathrm{x}$ \\
\hline Cultural loading & 125 & 20 & 54 & & 199 & 41.20 & 159 & 40 & 147 & 52 \\
\hline Culinary loading & 75 & 34 & 52 & $7(\mathrm{H})$ & 168 & 34.78 & 129 & 39 & 126 & 42 \\
\hline Compounding & 16 & 7 & 8 & & 31 & 6.42 & 30 & 1 & 30 & 1 \\
\hline Institutional concepts & 24 & & 2 & & 26 & 5.38 & 24 & 2 & 23 & 3 \\
\hline Connotative borrowings & 15 & 3 & 2 & & 20 & 4.14 & 16 & 4 & 16 & 4 \\
\hline Pluralisation & 7 & 3 & 5 & & 15 & 3.11 & 14 & 1 & 14 & 1 \\
\hline Transfer & 1 & & & 5 (Eng) & 6 & 1.24 & 6 & 0 & 6 & 0 \\
\hline Prefixation & 3 & & & & 3 & 0.62 & 3 & $\mathbf{0}$ & 2 & 1 \\
\hline Lexical shift & 3 & & & & 3 & 0.62 & 2 & 1 & 2 & 1 \\
\hline Polysemic variation & & & & 3(Eng) & 3 & 0.62 & 3 & 0 & 3 & 0 \\
\hline $\begin{array}{l}\text { Apostrophe showing } \\
\text { possession }\end{array}$ & 2 & & 1 & & 3 & 0.62 & 3 & 0 & 3 & 0 \\
\hline $\begin{array}{l}\text { Hybrids of non-English } \\
\text { origin used in formal and } \\
\text { informal situations }\end{array}$ & 1 & 1 & & & 2 & 0.41 & 1 & 1 & 1 & 1 \\
\hline Suffixation & 1 & 1 & & & 2 & 0.41 & 1 & 1 & 1 & 1 \\
\hline $\begin{array}{l}\text { Lexical items functioning } \\
\text { as a metaphor }\end{array}$ & 1 & & & & 1 & 0.21 & 0 & 1 & 0 & 1 \\
\hline Conversion & 1 & & & & 1 & 0.21 & 0 & 1 & 0 & 1 \\
\hline Total & 275 & 69 & 124 & $8 / 7$ & 483 & 100 & 391 & 92 & 374 & 109 \\
\hline
\end{tabular}

\section{Results and Discussion}

The researcher collected 483 lexical items from 261 sentences. Table 3 shows the collection of lexical items based on the 14 categories plus a new category, prefixation. The lexical items were arranged in descending order based on the frequency count of occurrences.

The collection of data reveals that most of the lexical items $(75.98 \%)$ fall under the cultural and culinary loadings. 199 lexical items (41.20\%) were collected under the cultural loading category followed by 168 lexical items $(34.78 \%)$ under the culinary loading category. The other categories follow subsequently. Compounding 
and institutional concepts categories consist of 31 lexical items which is $6.42 \%$ and 26 lexical items which is $5.38 \%$ respectively. There are 20 lexical items in the connotative borrowings category which constitute $4.14 \%$ of the total.

The pluralisation and transfer categories consist of 15 and 6 lexical items respectively which make up a total of $4.35 \%$ of the total collection. A total of 3 lexical items $(0.62 \%)$ were collected under the new prefixation category. A total of 9 lexical items were collected under the categories lexical shift $(0.62 \%)$, polysemic variation $(0.62 \%)$ and apostrophe showing possession $(0.62 \%)$. A total of 4 lexical items were collected under the categories suffixation $(0.41 \%)$ and hybrids of non-English origin used in formal and informal situations $(0.41 \%)$. Lastly, a total of 2 lexical items were collected under the categories conversion $(0.21 \%)$ and lexical items functioning as a metaphor $(0.21 \%)$.

Based on the research question the extent of use of the 3 main languages by the ESL teachers reveal that majority of the lexical items come from the Malay language followed by Indian languages and Chinese dialects. Out of the 483 lexical items collected, 275 lexical items are from the Malay language followed by 124 from Indian languages, 69 lexical items from the Chinese dialects, 8 English words and 7 lexical items related to "hybrid" dishes under the culinary loading category. This clearly shows that the main choice of language is Malay.

\subsection{Interrater Agreement}

The interrater agreement for the categorical items shows that rater A and rater B are in very good agreement. The calculation for $\mathrm{k}$ is 0.9 . The following steps show how $\mathrm{k}$ is calculated.

The 374 lexical items were accepted $(\sqrt{ })$ by both rater A and rater B and 92 lexical items were unaccepted (x) by both raters. Thus, the observed percentage agreement is $\operatorname{Pr}(\mathrm{a})=374+92 / 483=0.96$

\begin{tabular}{llllll}
\multirow{2}{*}{ RATER } & & \multicolumn{3}{c}{ RATER } \\
\cline { 3 - 5 } & & & $\mathrm{B}$ & $\mathrm{B}$ & \\
\cline { 2 - 5 } & & & $\sqrt{ }$ & $\mathrm{x}$ & \\
\cline { 2 - 6 } & $\mathrm{A}$ & $\sqrt{ }$ & 374 & 17 & 391 \\
& $\mathrm{~A}$ & $\mathrm{x}$ & 0 & 92 & 92 \\
\hline & & & 374 & 109 & 483
\end{tabular}

To calculate $\operatorname{Pr}(\mathrm{e})$ (the probability of random agreement):

RATER A accepted $(\sqrt{ }) 391$ lexical items and unaccepted (x) 92 lexical items. Thus rater A accepted $(\sqrt{ }) 80.95 \%$ and unaccepted (x) 19.05\%.

RATER B accepted $(\sqrt{ }) 374$ lexical items and unaccepted $(x) 109$ lexical items. Thus rater B accepted $(\sqrt{ })$ $77.43 \%$ and unaccepted $(\mathrm{x}) 22.57 \%$.

Therefore the probability that both the raters would accept $(\sqrt{ })$ randomly is $0.81 * 0.77=0.624$ and the probability that both the raters would unaccept is $0.19 * 0.23=0.044$. Thus the overall probability of random agreement is $\operatorname{Pr}($ “e”) $=0.624+0.044=0.668$

Applying the formula for Cohen's Kappa:

$$
\mathrm{k}=\frac{\operatorname{Pr}(\mathrm{a})-\operatorname{Pr}(\mathrm{e})}{1-\operatorname{Pr}(\mathrm{e})}=\frac{0.96-0.668}{1-0.668}=0.9 \text { (very good agreement) }
$$

According to the categories in Table 3, the following section portrays the usage of the lexical items under the prefixation category and for what purpose.

\subsection{Prefixation}

In the midst of data collection the researcher came across a new category and termed it as prefixation. Table 4 shows the 3 lexical items collected under the prefixation category, namely, non-halal (sentence 91), non-Bumiputera (sentence 208) and ex-qariah (sentence 209). The 3 lexical items collected were solely from the Malay language. According to the Oxford Advanced Learner's Dictionary (1998), prefix refers to a letter or a few letters added in front of a word to form a new word. The prefix "non-" refers to "not" or "the opposite of" and the prefix "ex-" refers to someone who is no longer what they were, former or earlier. These 3 lexical items portray an awareness of the rule of using the prefixation innovation. 
Table 4. Distribution of lexical items showing prefixation

\begin{tabular}{|c|c|c|c|c|}
\hline Sentence Number & Lexical items & Pattern (prefixation) & Rater A & Rater B \\
\hline & Malay: & & & \\
\hline 91 & non-halal & non + halal $=$ non-halal & $\sqrt{ }$ & $\sqrt{ }$ \\
\hline 208 & non-Bumiputera & non + Bumiputera $=$ non-Bumiputera & $\sqrt{ }$ & $\sqrt{ }$ \\
\hline 209 & ex-qariah & ex + qariah $=$ ex-qariah & $\sqrt{ }$ & $\mathrm{x}$ \\
\hline \multirow{2}{*}{$\begin{array}{l}\text { Total number of } \\
\text { sentences: } 3\end{array}$} & Total number of & & $\sqrt{ } 3$ & $\sqrt{ } 2$ \\
\hline & lexical items: 3 & & $\mathbf{x} 0$ & $\mathbf{x} 1$ \\
\hline
\end{tabular}

Sentences 91, 208 and 209 shows the lexical items which had gone through the process of prefixation.

\subsubsection{Sentence 91 (Prefixation, Language-Malay)}

Only halal food can be consumed by the Muslims, non-halal food is against their religion.

SAM Nurul Iman, (M, f, 37), 28.3.2012

(Written data: report)

Sentence 91 shows the use of Arabic terms halal and non-halal under the Islamic principles. Halal in sentence 91 refers to permitted food under the Islamic law while non-halal refers to not permitted under Islamic law, usually in reference to food and restaurants. But halal and non-halal can also refer to halal services and halal industry. Halal products and services are not only targeted and promoted within the global Muslim community but also among non-Muslims. The borrowing of Islamic terms into ME, either directly from Malay or from Arabic through Malay, suggests yet another motivation-one related to the assertion of the user's Islamic identity. This is to emphasise their religious affiliation (Tan, 2009). Since the Malays form the largest ethnic group in Malaysia, their religion of Islam has become an increasingly influential force in the Malaysian context of culture (Thirusanku \& Melor, 2012, p. 10).

\subsubsection{Sentence 208 (Prefixation, Language-Malay)}

The government is trying to encourage the non-Bumiputera to join the civil service.

SMK Rantau Panjang, (I, m, 44), 30.06.2012

(Written data: message)

The term non-Bumiputera refers to the person who lack Bumiputera status but have established himself in Malaysia and make up a considerable portion of the Malaysian population. Some Chinese and Indian families, known as "straits-born", have resided in Malaysia since as far back as the 15th century. Majority of Malaysia's Chinese and Indian populations are descended from migrants who arrived during the colonial period.

\subsubsection{Sentence 209 (Prefixation, Language-Malay)}

Ex-qariah champion Faridah Mat Saman said many budding talents have been wasted during the two decades of the ban on Kelantan women from entering the qariah competitions.

Kolej Islam Sultan Alam Shah, (M, m, 46), 30.06.2012

(Written data: newspaper article)

In sentence 209, the lexical item ex-qariah means previous women Quran reciters while qariah means women Quran reciters.

The results of these inflectional and derivational processes are hybridised forms which, according to Winford (2003, p. 44), are not technically the immediate outcomes of borrowing but "are really due to the more general process of integrating loan items into the morphology of the recipient language". To put it differently, borrowers apply recipient language morphosyntactic processes to previously imported words so that these words behave more like original recipient language words. In the same vein, Tan (2001) postulates that such inflectional and derivational processes are indications that the loanwords have become nativised to the linguistic system of the recipient language.

\section{Conclusion}

Data analysis reveals that the ESL teachers mainly use lexical items from the cultural loading category. Lexical items from Malaysian festivals were highly used compared to the other lexical items. The subsequent categories are as follows; culinary loading, compounding, institutional concepts, connotative borrowings, pluralisation, 
transfer, prefixation, lexical shift, polysemic variation, apostrophe showing possession, hybrids of non-English origin used in formal and informal situations, suffixation, lexical items functioning as a metaphor and finally conversion.

Festivals are important to Malaysians who are particular about traditions and beliefs. ESL teachers use lexical items that are related to the Malaysian culture and tradition to depict the multicultural society in Malaysia. These lexical items are extensively used by ESL teachers especially during festivals. This clearly shows that the three main cultures namely, the Malay, Chinese and Indian culture show pride in preserving their respective customs and beliefs. Lexical items are generally used when there are no exact English equivalents or when translated would cause the cultural elements to be lost. Hence, the ESL teachers prefer to use the lexical items as they are from the specific religion to depict the natural spirit of a festival (Thirusanku \& Melor, 2012, p. 8).

Cultural and culinary loadings have the highest lexical items due to the fact that traditional observances and food generally do not have equivalents in English. According to Chalaya (2008, p. 118), the local flavor will vanish if translated.

The analysis also portrays that the Malay lexical items are used frequently despite the races of the ESL teachers compared to lexical items from the other languages. This is due to the prestigious motive and also because most of the Malaysians are Malays. Other than that, the national language and the main medium of instruction in the schools in Malaysia is the Malay language. Therefore, every Malaysian is able to comprehend and speak it. The Malay language is the official language and considered prestigious in the Malaysian context. It is also because it has the highest degree of contact in their lives. Since it is the official language the Malaysians relate better to it. The lexical items 1Malaysia, Rukun Negara, muhibbah and open house are terms which are unique to the Malaysian culture which depict patriotism and unity.

Holding open house is a unique Malaysian trait. It not only promotes unity among the races but can also be put on the tourism calendar. According to Datuk Dr Victor Wee, Tourism Malaysia chairman, this is the beauty of our country, people open up their homes to those from different walks of life. Even Prime Minister Datuk Seri Najib Razak, during his Hari Raya open house expressed happiness that Malaysians held this practice abroad, including serving lemang, ketupat and rendang to guests. He described the open house tradition as a unique practice adopted by Malaysians to mark festivities. "The spirit of 1Malaysia is seen in the Hari Raya open house. People from all walks of life mix with one another," said tour operator Datin Baizura Abu Bakar (NST, 2012, p. $1)$.

It is just the nature of Malaysians to be hospitable and the glue that binds them together in hospitality is food. It awakens the senses but the food-centric behaviour is also about being in good company, feeling at home, celebrating the good things and resolving issues. From the smallest home to the largest of events, there are many rich culinary and hospitality traditions that now swirl naturally in the social melting pot and have contributed to their identity. That is how the Malaysians have come to own the much-celebrated open house, an idea that begins in the heart.

Furthermore, the high use of lexical items under the cultural and culinary loadings is because of the absence of objects or concepts in the English culture. This is referred to as the cultural gap between cultures. Hockett (1958) refers to this as the need-filling motive whereby it is necessary to use concepts and ideas when there are no equivalents.

In addition, the use of the lexical items from the 3 main languages by ESL teachers is to retain the original flavor of the situation. For instance, when describing Thaipusam, the lexical items pal kudam and kavadi are used to portray the local flavor of the festival. These lexical items are retained to depict the Hindu cultural tradition and individuality.

The analysis also reveals that even though some lexical items can be translated into English, in many situations, it is not done so. In order to be comprehended by everyone, the ESL teachers prefer to be specific and clear with their spoken and written discourse. This is due to the convenience factor. Most importantly, it is because of the constraint of time in the spoken and written discourse. Thus, the lexical items are maintained to transmit messages quickly and precisely.

To summarise the reasons for the use of the lexical borrowings by the ESL teachers, the vast majority of borrowed features in ME are derived from the need to refer to local objects and cultural constructs for which there are no pre-existing English words. Most of the lexical items listed under the 15 categories specifically, under the cultural and culinary loadings do not have equivalents in English. The prolific borrowing of such items can be explained in terms of the retention of the cultures and traditions by many Malaysians regardless of 
ethnicity.

Local dishes and indigenous foodstuffs namely, thosai, dhal, bak kut teh, yee sang, rendang and serunding are ubiquitous elements of the local gastronomic scene. Despite the pervasiveness of western games and sports traditional games and art of self-defence and exercises namely, silambam, kabadi, mahjong, tai chi, congkak and silat are still enjoyed by various segments of the society. Even though jeans, T-shirts, dresses, suits and jackets are commonly worn, traditional clothes namely, saree, veshti, samfoo, cheongsam, baju kurung and baju Melayu are worn during celebrations and festivals. Religious terms and observances namely, pal kudam, kavadi, Qing Ming, feng shui, umrah and haj continue to be important parts of the belief system of the society.

Sometimes, ME users adopt local words in order to make finer distinctions of meaning. For instance, instead of using the words top and kite, gasing and wau are used to differentiate the huge top that has a weight of 5 kilograms from the small top which is a small conical plaything tapering to a steel point on which it can be made to spin and to distinguish the large local kite, usually flown by adults after the rice harvesting season, between May and July, from the small kite which refers to a light framework covered with cloth, plastic or paper, designed to be flown in the wind at the end of a long string, respectively. Similarly, instead of using the word dais, pelamin is used, which refers to a Malay wedding dais specifically for the bersanding ceremony. Baju kurung Kedah, kebaya and shalwar kameez are diverse styles of traditional attire worn by Malaysians.

Some phrases also convey specific undertones that are difficult to replicate using the existing English words. These phrases are used for borrowing namely, bunga manggar which refers to a fake decorated tree used during any auspicious ceremony. This is an important aspect for the Malays, especially during weddings. Another example is the bunga telur, a hard boiled egg beautifully decorated in a form of a flower stalk, which symbolizes fertility and distributed to everyone present for the Malay wedding. Finally, rashi and feng shui which refers to the Indian horoscope and the element of luck in the Chinese culture respectively.

Certain lexical items especially those listed under the semantic field of government, administration and the monarchy, appear to be motivated by nationalism namely Rukun Negara, a declaration issued on 1970 Merdeka Day for unity and peace among the Malaysians after the May 13 issue in Malaysia, muhibbah which means harmonious, associated with good will and friendship among different groups of the society and Malaysia Boleh, literally means "Malaysia Can" is a slogan used to promote national pride. The can-do attitude encapsulated in this slogan became known as the Malaysia Boleh spirit. This phrase was extensively used by the Malaysians after reaching the Mount Everest summit and followed by the $16^{\text {th }}$ Commonwealth games. Incorporation of these terms in Malaysian English highlights the status of the national language and its role as government language and administration of Malaysia. This depicts the Malaysian spirit of unity and success (Thirusanku, 1999, p. 25).

Besides this, the presence of a new innovation was identified in this study that is prefixation (see Table 4). According to the Oxford Advanced Learner's Dictionary (1998), prefix is a letter or a few letters used in front of a word to form a new word. "Non-" is a prefix which refers to "the opposite of" or "not". Two lexical items identified in this study were non-halal (sentence 91) and non-bumiputera (sentence 208). "Ex-" is a prefix which refers to a person who is no longer what they were, earlier or former, one lexical item identified in this study was ex-qariah (sentence 209). Just like suffixation, prefixation can be considered as a new category in future studies.

Overall, the lexical items in this study were used to connect the idea with the speakers and readers in Malaysia. It also depicts that the English language is flexible and willing to accept the lexical items from the Malay, Chinese and Indian languages to suit the Malaysian culture. The lexical items are borrowed directly to ensure that the linguistic and cultural identities of the borrowed terms are preserved. The borrowed terms have developed a range of meanings that are an extension of the original meanings as well as new meanings. Such a combination would in all likelihood enhance and enrich the language and culture. Hence, this adds to the uniqueness of Malaysian English.

According to Richards (1979), indigenization occurs when the English language in a society experiences changes slowly until it attains a personal communicative function. Borrowers are conditioned not only by their need to expand the communicative and expressive powers of English but also by their need to integrate the borrowed features into the linguistic system of the English language (Tan, 2009, p. 451). Thus, the usage of lexical items has enriched the English variety in Malaysia. The use of borrowings indicates that the ESL teachers in Malaysia have accepted them.

The language role has widened and it is very flexible now. Consider this study for instance, the massive amounts of borrowings, 483 lexical items collected from the ESL teachers are actually new classifications with regards to borrowing, a great contribution in the field of ME. Therefore, Malaysian English is rapidly changing politically, economically and also socio-culturally to suit the needs of the multi-cultural society in Malaysia. The 
preservation of culture and traditional practices within a multilingual society that maintains the regular use of a localised variety of English creates ideal contact conditions for the transmission of words and phrases from one language to another. The generally positive attitude that Malaysians have towards their own variety of English and the continuing relevance of culture and tradition in Malaysia mean that lexical borrowing will likely continue to generate stable and observable changes in Malaysian English.

Thus, with the use of the Standard Malaysian English, Malaysians can be further united and patriotic and accept the 1Malaysia concept with a more open and positive mind. 1Malaysia (pronounced Satu Malaysia in Malay) is an on-going programme designed by Malaysian Prime Minister Najib Tun Razak on 16 September 2010, calling for the cabinet, government agencies and civil servants to more strongly emphasise ethnic harmony, national unity and efficient governance. With a formal, educated variety of Malaysian English, togetherness and a sense of belonging among Malaysians will be a stepping stone to achieve the 1Malaysia concept. The 1Malaysia concept will naturally have a strong impact among the Malaysians. As Malaysians we have to stand united despite our races and diverse cultures, think and act as Malaysians. A nation of communities that make up 1Malaysia. This is only possible with the implementation of a local variety, the Standard Malaysian English or to be made known as 1Malaysia English, the English that unites the Malaysians.

The Standard Malaysian English is a tool to foster unity. Intercultural exchange among people of various races plays a vital role in ensuring that national unity can be achieved. The Standard Malaysian English can be used as a medium to improve intercultural exchange among people of various races. Through the Standard Malaysian English we can get to know others, our differences can be overcome and we can introduce the Malaysian culture to the world.

ESL teachers are always looking for ways and measures to improve the teaching and learning of English in schools in order to keep our learners interested and motivated to learn English. Thus, what other better way than to use a local variety with the correct approach. Therefore, with the Standard Malaysian English and the correct approach, our learners will be able to understand and connect easily. When the fear factor is decreased, learning is increased. Based on this, a compulsory pass in the 1119 English paper for the SPM examination in 2016 will not be a problem at all.

According to Mufwene (2001) and Schneider (2007), all varieties of English develop from similar stimuli and through similar processes. All varieties must, on the one hand, reflect the cultural realities of the speaker and on the other, be adaptable enough to allow international communication (cited in Thirusanku \& Melor, 2012, p. 8). Nativised English is acceptable for communicating socially and informally and gives one a strong sense of identity (Gill, 2002a, p. 47, cited in Thirusanku \& Melor, 2013, p. 27). This is reflected by the distinct phonology influenced by their ethnic tongues, lexical items which are socio -culturally grounded and syntactic structures which are distinctly Malaysian in form. This is to create rapport and establish a sense of identity (Gill, 2002a, p. 91, cited in Thirusanku \& Melor, 2013, p. 28). Therefore, the use of 1Malaysia English should not be suppressed because it gives a sense of identity to its users.

\section{References}

Anthonysamy, J. (1997). Lexico-semantic variations in Malaysian English (Unpublished Master Thesis). University of Malaya, Kuala Lumpur.

Audience Dialogue, Observation Techniques. (2006). Retrieved January 17, 2012, from $\mathrm{http}: / / \mathrm{www}$.audiencedialogue.net/kya13.html

Augustin, S., \& Palansamy, Y. (2012, August). Open house can be huge tourist draw. New Straits Times, 23, 1.

Baskaran, L. (1985). The New Englishes. Jurnal Bahasa Moden. English as a World Language (pp. 68-95). Cambridge: Cambridge University Press 6.

Baskaran, L. (1987). Indigenisation of English (Malaysian English-Its Development and Features). Paper presented at the Modern Language Association Conference on The Language Situation in Malaysia? in Kuala Lumpur, Malaysia.

Baskaran, L. (1987). Aspects of Malaysian English Syntax (Unpublished Ph.D Thesis). Department of Linguistics, University of London.

Baskaran, L. (2004a). In B. Kortmann et al. (Eds.), Malaysian English: Morphology and syntax (pp. 1073-1085).

Baskaran, L. (2004b). In E. W. Schneider et al. (Eds.), Malaysian English: Phonology (pp. 1034-1046).

Chalaya, P. (2008). Lexical borrowings from Malaysian substrate languages in local English dailies (Unpublished Masters Thesis). University of Malaya, Kuala Lumpur. 
Choudhury, A. (2010). Cohen's Kappa. Retrieved July 7, 2014, from https://explorable.com/cohens-kappa

Department of Statistics Malaysia. (2010). Retrieved January 17, 2010, from http://www.statistics.gov.my/portal/

Gill, S. K. (2002a). International Communication: English Language Challenges for Malaysia. Serdang: Universiti Putra Malaysia.

Grolier International Dictionary. (2000). World English in an Asian Context. Macquarie University, NSW: The Macquarie Library.

Hornby. (1998). Oxford Advanced Learner's Dictionary or Current English. Oxford: Oxford University Press.

Hockett, C. F. (1958). The Conditions of Borrowing. A Course in Modern Linguistics. New York: The Macmillan Company. http://dx.doi.org/10.1111/j.1467-1770.1958.tb00870.x

Lowenberg, P. H. (1986). Sociolinguistic Context and Second-Language Acquisition: Acculturation and Creativity in Malaysian English. World Englishes, 5(1), 71-83. http://dx.doi.org/10.1111/j.1467-971X.1986.tb00641.x

Low, E. L., \& Hashim, A. (Eds.). (2012). English in Southeast Asia: Features, policy and language in use. Amsterdam: John Benjamins Publishing co. http://dx.doi.org/10.1075/veaw.g42

Macquarie Junior Dictionary. (1999). World English-Asian Context. Macquarie University, NSW: Macquarie Library.

Menon, D. (2003). Non-native Features in the Lexis of Malaysian English (Unpublished Ph.D Thesis). University of Malaya, Kuala Lumpur.

Mufwene, S. S. (2001a). African-American English (pp. 291-324).

Mufwene, S. S. (2001b). The Ecology of Language Evolution. Cambridge: Cambridge University Press. http://dx.doi.org/10.1017/CBO9780511612862

Ooi, V. (2001). Upholding Standards or Passively Observing language. Corpus Evidence and the Concentric Circles Model. In V. Ooi (Ed.), Evolving Identities: The English Language in Singapore and Malaysia. Edited by Vincent Ooi, Singapore: Times Academic Press.

Richards, J. C. A. (1979). Rhetorical and Communicative Styles in the New Varieties of English. Language Learning, 29(1), 1-25. http://dx.doi.org/10.1111/j.1467-1770.1979.tb01049.x

Schneider, E. W. (2007). Postcolonial English: Varieties around the world. Cambridge: University Press. http://dx.doi.org/10.1017/CBO9780511618901

Selinker, L. (1972). Interlanguage. International Review of Applied Linguistics in Language Teaching, 10(3), 209-231.

Strevens, P. (1981). Forms of English. In L. Smith, (Ed.), An Analysis of the Variables In English for Cross Cultural Communication. New York: St. Martin Press.

Tan, P. K. W. (2001). Melaka or Malacca; Kallang or Care-Lang: Lexical innovation and nativisation in Malaysian and Singaporean English. In V. Ooi (Ed.), Evolving Identities: The English Language in Singapore and Malaysia. Singapore: Times Academic Press.

Tan, S. I. (2009). Lexical Borrowing in Malaysian English: Influence of Malay (pp. 11-62). Lexis: Borrowing/L'emprunt.

Tan, S. I. (2009). Lexical borrowing from Chinese languages in Malaysian English. World Englishes, 28(4), 451-484. http://dx.doi.org/10.1111/j.1467-971X.2009.01607.x

Thirusanku, J. (1999). An Analysis of Lexical Borrowings of Malaysian English in the Compositions of Form Two Students (Unpublished Masters Thesis). Universiti Putra Malaysia, Serdang.

Thirusanku, J., \& Melor, M. Y. (2012). The Many Faces of Malaysian English. International Scholarly Research Network, 2012, 14.

Thirusanku, J., \& Melor, M. Y. (2012). The Usage of Malaysian English Lexis by ESL Teachers. Proceedings of the $3^{\text {rd }}$ International Conference on Learner Diversity, 15-28. UKM, Malaysia.

Thirusanku, J., \& Melor, M. Y. (2012). Malaysian English the key to 1Malaysia. Proceedings of the National Research and Innovation Conference on Social Sciences for Graduate Students, 529-550. UPM, Malaysia. 
Thirusanku, J., \& Melor, M. Y. (2013). Malaysian English-A Distinct Variety. Internet Journal of Language, Culture and Society, 37, 18-29.

Times-Chambers Essential English Dictionary. (2nd ed.). (1997). Singapore: Federal Publications and Edinburgh: Chambers Harrap.

Winford, D. (2003). An Introduction to Contact Linguistics. Oxford: Blackwell.

\section{Copyrights}

Copyright for this article is retained by the author(s), with first publication rights granted to the journal.

This is an open-access article distributed under the terms and conditions of the Creative Commons Attribution license (http://creativecommons.org/licenses/by/3.0/). 